\title{
Excellent gamer, excellent driver? The impact of adolescents' video game playing on driving behavior: a two-wave panel study
}

Beullens, Kathleen; Roe, Keith and Van den Bulck, Jan

Leuven School for Mass Communication Research, Katholieke Universiteit Leuven

Parkstraat 45 (bus 3603), 3000 Leuven (BELGIUM)

Corresponding author: Kathleen Beullens, e-mail: Kathleen.Beullens@soc.kuleuven.be

Tel: +32(0)16.32.32.19//+32(0)16.32.32.20 Fax: +32(0)16.32.33.12

Keith Roe: e-mail: Keith.Roe@soc.kuleuven.be

Jan Van den Bulck: e-mail: Jan.VanDenBulck@soc.kuleuven.be

Accepted author manuscript, article published in Accident Analysis \& Prevention:

Beullens, K., Roe, K., \& Van den Bulck, J. (2011). Excellent gamer, excellent driver? The impact of adolescents' video game playing on driving behavior: A two-wave panel study. Accident Analysis and Prevention, 43, 58-65. DOI: 10.1016/j.aap.2010.07.011.

Published version: $\underline{\text { http://www.sciencedirect.com/science/article/pii/S0001457510001995 }}$ 


\begin{abstract}
This study explored the impact of adolescents' playing of racing and drive'em up games on their risky driving behavior. Participants were 354 adolescent boys and girls who took part in a longitudinal panel survey on video game playing and risk taking attitudes, intentions and behaviors. In line with cultivation theory and theory of planned behavior the results showed that (even after controlling for aggression and sensation seeking) video game playing during adolescence succeeded in predicting later risky driving behavior through adolescents' attitudes and intentions to exhibit this behavior in the future. The results suggest that this relationship may in part be explained the game content.
\end{abstract}

Keywords: traffic; risk taking; video games; adolescents; alcohol; speeding 
Excellent gamer, excellent driver? The impact of adolescents’ video game playing on driving behavior: a two-wave panel study

\section{Introduction}

Worldwide more than 1000 people a day under 25 die as a result of a traffic crash (World Health Organization (WHO), 2007). Despite all efforts to reduce the number of injuries and deaths on world's roads, traffic crashes remain the leading cause of death among young people (WHO, 2007).

Research has indicated that the high crash involvement among this group is partly explained by their risk taking propensity (Arnett et al., 2002; Ulleberg and Rundmo, 2002). Although risky driving has been found to be associated with a certain lifestyle (Bina et al., 2006; Chliaoutakis et al., 1999, 2005; Gregersen and Berg, 1994;) and media use is an important aspect of adolescents' lifestyle (Gorely et al., 2007), the relationship between media use and risky driving has not yet been examined thoroughly. Adolescent boys' and girls’ video game playing merits particular attention. In racing and drive'em up games, the player takes the position of driver and drives in a city or on a racing track. The objective of the racing game is to get to the finish first. In the case of drive'em up games points can also be gained by running into other cars or pedestrians, and finishing first is not an absolute requirement to win the game. In both genres risky driving behaviors such as speeding, fun riding (that is, taking risks in traffic in order to make driving more fun) and asocial driving behavior are extremely present in an often photographically realistic environment (Beullens et al., 2008).

Video game playing is a very popular pastime among adolescents (Malliet, 2007; Van Mierlo and Van den Bulck, 2004). Cummings and Vandewater (2007) have found that 36\% of 
American adolescents games regularly. $80 \%$ of the players are boys, who play an average of 58 minutes during weekdays and 1 hour and 37 minutes during the weekend. Girls play less often and for shorter time periods than boys do. In the weekend they play on average a little bit more than 1 hour, during weekdays 44 minutes. Van Mierlo and Van den Bulck (2004, p. 105) also found significant discrepancies in adolescent boys' and girls' video game playing. Boys spent on average 31 hours and 15 minutes a month playing games, whilst girls spent 6 hours and 39 minutes. Racing and drive'em up games appear to be very popular game genres among boys and girls (Lucas and Sherry, 2004). Given their popularity and the fact that these games are much more realistic than they were about 10 years ago, extensive exposure to these games may have an impact on young people’s driving behavior.

Several studies have found a relationship between video game playing and traffic related risk taking. Fisher et al. (2007) examined whether playing particular racing games affects risk taking cognitions, affect and behavior. In a first, cross-sectional, study they found a positive association between the amount of video game playing and self-reported obtrusive and competitive driving, and crash involvement. A negative relationship was observed between gaming and traffic cautiousness. More game playing was associated with reduced self-reported cautious road behavior. Study 2 and 3 examined experimentally whether playing racing games results in a higher accessibility of risk-related cognitions and affects (study 2) and individual willingness to take risks in traffic (measured with a computer system) (study 3). The results indicated a positive effect of 20 minutes of racing game playing on the accessibility of risk-promoting cognitions, on feelings of arousal/excitement and on participants' readiness to take risk in traffic (Fisher et al., 2007). In a subsequent study, Fisher et al. (2008) found that people exposed to risk-promoting images, movies scenes and video games are more inclined to take risks in traffic. The authors explained these findings from the perspective of priming theory. Exposure to risk promoting games is expected to increase the 
accessibility of risk taking cognitions, which in turn are supposed to result in an increase of risk-taking inclinations. Beullens et al. (2008) examined the impact of adolescents' playing of racing and drive'em up games on their intentions to engage in risky driving. Their results indicated that video game playing is a positive predictor of adolescents' attitudes toward fun riding, which predicted their intentions to engage in this behavior in the future.

The present study is an extension of this line of research by looking at the relationship between video game playing and risky driving longitudinally. Fischer et al. (2007, 2008) have expressed the need for longitudinal research in examining the impact of media on risk taking in traffic. Although the previously mentioned studies have indicated that there is a cause for concern since there appears to be a relationship between risk stimulating media such as racing games and drive'em up games and risky driving cognitions, attitudes, intentions and inclinations, these studies have only dealt with short-term effects (Beullens et al., 2008; Fischer et al., 2007, 2008). However from a prevention point of view it is important to know whether these effects persist for longer periods of time. Second, previous research has focused on risk taking inclinations. Consequently, the question to whether these inclinations translate into driving behavior has remained unanswered. Therefore the present study used a longitudinal panel survey to examine whether adolescent boys’ and girls’ video game playing has an impact on their self-reported driving behavior.

\subsection{Aim of the study}

The aim of the study is to examine whether adolescent media use, at the time that they do not have their driver's license yet, is a significant predictor of their self-reported driving behavior 2 years later. This research is framed within cultivation theory (Gerbner and Gross, 1976; Gerbner et al., 1986) and theory of planned behaviour (TPB) (Ajzen, 1991). Cultivation theory proposes that television is an important source of socialisation and information. 
Cultivation theorists state that there are important discrepancies between the world as it is depicted on television ('television world') and the 'real world'. Since heavy television viewers are constantly exposed to similar images on television, they cultivate perceptions and attitudes similar to the television world (more than light viewers do). Thus, according to cultivation theory frequent exposure to similar television content may, in the long term, result in the development of a world view similar to the one depicted on television and may lead to alterations in its viewers' perceptions and attitudes (Gerbner and Gross, 1976; Gerbner et al.,1986). TPB, on the other hand, argues that attitudes are an important predictor of behavior through the intention to perform this behavior in the future (Ajzen, 1991; Armitage and Conner, 2001). Attitudes are in turn, according to the theory, determined by behavioral beliefs. These are defined as the subjective probability that a particular behaviour leads to a given outcome (Ajzen, 1991).

The theoretical framework used in this study draws upon a combination of both theories. Although cultivation theory originally only dealt with television effects, a number of researchers have used it to examine the impact of games (Van Mierlo and Van den Bulck, 2004; Williams, 2006). Several important distinctions with television viewing must be taken into account. First, playing video games differs significantly from television viewing (Van Mierlo and Van den Bulck, 2004; Williams, 2006). Compared to television viewing, gaming is much more active. The player is more actively involved in the game and may even influence the game by making particular choices. Van Mierlo and Van den Bulck (2004) argue that this active involvement may result in a higher impact of video games than television. Second, video games’ content is very diverse. Cultivation theory originally stated that television content is rather homogenous and that television viewing is non-selective and ritualistic. This viewing behavior is expected to result in the cultivation of a world view that is similar to the one that is portrayed on television. These assumptions of a uniform television 
content and ritualistic viewing have been heavily criticized in later cultivation research. Potter (1993) as well as Cohen and Weimann (2000), and Bilandzic and Rössler (2004) have argued that different genres focus on different aspects of reality and therefore have different effects. This is also the case for video games. While it may be argued that particular content (e.g. violent behavior cf. Van Mierlo and Van den Bulck, 2004, p. 99) appears in virtually all games, this is certainly not the case for driving behavior. Risky driving is present in racing and drive'em up games and hardly ever appears in other game genres. This implies that frequent players might not be exposed to risky driving in video games. Thus, in line with authors (e.g. Bilandzic and Rössler, 2004; Cohen and Weimann, 2000; Potter, 1993) looking at genre-specific cultivation effects of television viewing; the specific effects of the playing of racing and drive'em up games will be examined in the present study.

Several authors have used cultivation theory in examining video game effects. Anderson and Dill (2000) found a positive association between exposure to aggressive video games and feelings of safety. However, this relationship disappeared when gender was controlled for. No significant relationship was found between game playing and crime likelihood estimations. Van Mierlo and Van den Bulck (2004), however, did find a positive association between violent video games and estimations of the number of policemen on the one hand, and estimates of the prevalence of violent crime on the other hand. Williams (2006) also concluded that support was found for a cultivation effect of video games based on the results of an experiment. Apart from these studies which explicitly referred to cultivation theory several other researchers (mainly in research on the effects of gaming on aggression) have found associations between video game play, attitudes and behavior. In line with these results, cultivation theory and TPB, the present study examines the relationship between the playing of racing and drive’em up games and several risky driving behaviors. 


\subsection{Hypotheses}

Following cultivation theory, it is expected that the frequent playing of racing and drive'em up games may alter players’ perceptions and attitudes towards risk-taking in traffic. Three particular forms of risky driving were scrutinized: speeding, fun riding and driving after the consumption of alcohol. Speeding and fun riding are two forms of risky driving which are very closely related to the content of racing and drive'em up games. In these games points can be gained by winning a race or by driving recklessly. Consequently, and in line with cultivation theory, it is expected that the long term exposure to these forms of risky driving in racing and drive'em up games is associated with positive attitudes towards these forms of risk taking. Unlike speeding and fun riding driving after the consumption of alcohol is largely absent from the story line of about all video games. Thus, this dependent measure is added in order to falsify our theoretical framework. Since it is expected that long term exposure to a particular type of content may result in more positive attitudes toward the depicted forms of risk taking no relationship should be found between the playing of racing and drive'em up games and forms of risky driving not portrayed in these games. Therefore it is expected that the playing of these games is not significantly related to attitudes toward driving after the consumption of alcohol. This resulted in the following hypothesis:

H1a: The amount of playing of racing and drive'em games is a positive predictor of the attitudes towards fun riding and speeding.

H1b: The amount of playing of racing and drive'em up games is not a significant predictor of the attitudes toward driving after the consumption of alcohol.

Although cultivation theory deals with changes in perceptions or attitudes as a result of media exposure, it does not in itself explain changes in behavior. TPB on the other hand provides a 
framework for examining the relationship between attitudes and behavior. In line with TPB it is hypothesized that attitudes toward risk taking in traffic succeed in predicting a significant part of young adults’ risky driving behavior, through the intention to perform this behavior. This resulted in the following hypotheses:

H2: Attitudes towards risky driving are a good positive predictor of the intention to engage in this behavior.

H3: The intention to engage in risky driving during adolescence is a positive predictor of self-reported driving behavior two years later.

In the model proposed in this study two personality characteristics were controlled for: physical aggression and the intensity factor of sensation seeking. Several researchers (see: Fisher et al., 2008) have underlined the importance of the inclusion of personality characteristics in studies examining the predictors of risky behavior in traffic, while they have been found to be associated with both risky driving and media use. Arnett (1996), for example, found that aggression and sensation seeking were positively related to several forms of risk-taking in traffic. Jonah (1997) concluded that a large number of studies posited that sensation seeking is positively associated with several forms of reckless driving. Correlations varied between 0.30 and 0.40 depending on the measures used and the subgroups under examination. Fishbein (2000), and Fishbein and Cappella (2006) both saw personality characteristics as indirect predictors of risky driving behavior. Ulleberg and Rundmo (2003) considered the relationship to be indirect. In their model personality characteristics predicted a significant part of the variance in risk behavior indirectly, through attitudes. Furthermore several studies have reported a relationship between media use and personality characteristics. Anderson and Dill (2000, p. 781) found that for men scoring high on trait aggression a 
positive relationship existed between video game playing and aggressive behavior. Kirsch (2003, p. 383) argued in his study on the impact of video games on adolescents that biological and psychological changes in adolescence may result in aggressive behavior and that adolescents scoring high on aggression may prefer different media content compared to less aggressive adolescents. Similarly the results of Lemmens and Bushman's (2006) study indicated that aggressive and less empathic adolescent males have a preference for violent video games and play them more often than non-violent games. In line with these results two personality characteristics, namely sensation seeking and aggression were controlled for in the models. This resulted in the following hypotheses:

H4: Aggression and sensation seeking are (direct) positive predictors of video game playing.

H5: Aggression and sensation seeking predict risky driving directly and indirectly through video game playing and the attitudes towards risk taking in traffic.

Together these hypotheses lead to the theoretical model (figure 1) concerning the relationship between video game play and risky driving.

\section{FIGURE 1: ABOUT HERE}

This theoretical model will be tested for several subgroups. Statistics indicate that young men appear to be at greater risk to be involved in traffic crashes than young women (BIVV, n.d., p. 16). In addition important differences have been reported in the amount of video game playing among men and women (cf. infra). Therefore multiple group analyses will be performed in order to examine whether gender is a significant moderator for the relationship between video game playing and risky driving. 
In the current study a two wave panel survey design was used to examine whether adolescent boys’ and girls’ playing of racing and drive'em up games predicts their speeding and fun riding two years later. Following a combination of cultivation theory and TPB it is hypothesized that this relationship is mediated through the attitudes towards reckless driving and risky driving intentions.

\section{Method}

\subsection{Sample}

For the first wave of data collection questionnaires were administered to a stratified random sample of secondary school students in Flanders, Belgium. From the official list of secondary schools in Flanders 20 schools were randomly selected. These schools were contacted with the request to cooperate in a large-scale study on the relationship between media use and risk behavior among adolescents. When a school agreed to cooperate, all students from the fifth and sixth year were included in the sample. This selection procedure was repeated until 15 schools agreed to cooperate in the study.

In the weeks following sample selection research assistants visited the selected schools to administer the questionnaires. The study was presented to the pupils as a study on leisure activities (part 1) and traffic (part 2). In total 2193 pupils filled out a standardized, selfadministered questionnaire including measures of video game playing and risky driving. $65.2 \%$ of the students were boys, $34.8 \%$ were girls. $41.7 \%$ of the respondents were born in 1988, 36.5\% in $1989(\mathrm{M}=1988$, $\mathrm{StD}=.93)$, thus the large majority of our respondents were 17 or 18 years old at time 1. In Flanders a definitive driver's license can only be obtained at the age of 18. A large majority (91.3\%) of the respondents in the first wave did not yet have their driver's license during data collection. As a result, their self-reported driving behavior was not assessed in the questionnaire. 
The strict confidentiality of the respondents' answers was stressed before as well as after the completion of the questionnaire. Next, the respondents were informed that a followup study was planned two years later and they were asked whether they agreed to cooperate in the second part of the study. Students who promised to collaborate were asked to provide their home address as well as their e-mail address. In total $89.5 \%$ agreed to take part in the second wave of the study and provided their home address, 71.3\% provided their e-mail address.

Two years after the first wave of data collection the second wave was administered. First, a follow-up web survey was sent to all the students who had provided their e-mail account. 31.5\% of the e-mails returned to the sender because of mistakes in the e-mail addresses or because the addresses did not exist anymore. In line with the Total Design Method (Billiet and Carton, 2001) two follow-up e-mails were sent after the first contact. In sum this resulted in the completion of 552 websurveys, this is $51.5 \%$ of the respondents who provided a valid e-mail address.

Second, respondents who had not yet answered were sent a paper version of the questionnaire and a stamped and addressed envelope at their home address. Two weeks later a letter was sent to thank all the respondents who had already taken part in the second wave of the study and to encourage the others to fill out the questionnaire and send it back to the researcher. Two weeks later a third reminder (which included a new questionnaire and return envelope) was sent to those respondents who had not yet answered. In total this resulted in 552 completed questionnaires. The postal survey and the websurvey together resulted in a response of 1104 respondents. Thus $50 \%$ of the respondents who completed the first questionnaire took part in the second wave of the study.

The aim of the current study is to examine the relationship between video game playing during adolescence and risky driving two years later. Only those respondents who completed both waves and had obtained their driver's license in the second wave of the study 
were kept for the analyses. This is a subsample of 354 young persons, $62.7 \%$ were boys, $37.3 \%$ girls, $53.8 \%$ were born in $1988,29.7 \%$ in 1989 and $14.4 \%$ in 1987 . Consequently most of the respondents in the subsample on which the analyses were run were 17 or 18 years old at time 1 and 19 or 20 years old at time $2.42 \%$ of the boys and $31.1 \%$ of the girls without driver's license at time 1 had obtained their driver's license at time 2. Chi-square analyses indicated that the boys differed significantly from the girls in this matter $\left(\chi^{2}=11.832, \mathrm{df}=1\right.$, $\mathrm{p}<.01)$

The study and sampling method were approved by the Institutional Ethics Committee of the Katholieke Universiteit Leuven and permission to interview the children was obtained from the legal guardians of the children.

\subsection{Measures}

Respondents were given a list of various video game content types. They were asked (1) 'how often do you play racing games on a circuit such as Gran Turismo, Ridge Racer, MotoGP,...' (2) 'Drive'em up games such as Driver, Carmageddon, Burnout, Need for Speed,...'. Response categories were (0) never, (1) a few times a year, (2) about once a month, (3) a few times a month, (4) about once a week, (5) a few times a week, (6) (almost) every day.

Ulleberg and Rundmo (2002) validated an instrument to measure young drivers’ risk taking attitudes. This instrument consists of 11 dimensions, 3 of them - attitudes towards joyriding (fun riding), speeding and drinking and driving - were translated into Dutch and used in the questionnaire. A principal components factor analysis with oblique rotation (Direct Oblimin) yielded the same factor structure as Ulleberg and Rundmo found. Cronbach's Alpha was calculated for each factor: fun riding $(\alpha=.78)$, speeding $(\alpha=.80)$ and drinking and driving $(\alpha=$.75). This measure gives an indication of the internal consistency of 
the scale. Generally values larger that .70 are considered to be acceptable, although lower thresholds are sometimes considered to be tolerable if the scale contains few items (Carlo, Eisenberg \& Knight, 1992; Cortina, 1993; Nunnally, 1978; Santos, 1999).

Sensation Seeking was questioned using Arnett's Inventory of Sensation Seeking (AISS) (Arnett, 1994). Haynes et al. (2000) analyzed AISS and Zuckerman’s Sensation Seeking Scale Form V and concluded that a modified version of AISS provides a more appropriate measure of sensation seeking. The original AISS consists of 20 items and is made up of two subscales: intensity and novelty. For the current study only the intensity factor was used in the analyses, since it was felt that this factor was most closely related to video game playing. Principal components analysis indicated that 6 items of the original scale loaded on the intensity factor. Two items were removed from the factor since they referred to media content (e.g. 'I like a movie where there are a lot of explosions and car chases'). 4 variables (items 8, 16, 18, 20 from the original scale) loaded onto the intensity factor and were kept in the analyses (Cronbach’s Alpha =. 57). Physical aggression was measured using Buss and Perry’s (1992) Aggression questionnaire (Cronbach’s Alpha=.81). Responses for both personality characteristics ranged from (1) do not agree at all, (2) do not agree, (3) agree to (4) totally agree.

Respondents' intention to engage in speeding, fun riding and driving after consuming alcohol was measured as part of a series of questions regarding risky driving behavior. Intention has been defined by Fishbein and Ajzen (1975, p. 288) as “[...] a person’s subjective probability that he will perform some behavior”. Respondents had to indicate whether they thought they would (1) drive faster than allowed, (2) drive while they might have had too much alcohol, (3) drive while they had definitely had too much alcohol, (4) take risks to make driving more fun in the future (5) drive faster than allowed on the highway. Response categories were (0) never, (1) seldom, (2) sometimes, (3) often, (4) very often and 
(5) always. Item 1 and 4 were used as measure for fun riding intentions. Items 2 and 3 both loaded on the latent drinking and driving variable and items 1 and 5 were used as measure for speeding intentions (Beullens et al., 2010, in press).

Respondents were asked: (1) How often do you drive fast for the thrill of it?; (2) How often do you take risks when driving to make driving more fun?; (3) How often do you drive faster than allowed on the open road. Response categories were (0) never, (1) seldom, (2) sometimes, (3) often, (4) very often and (5) always. These items are part of Begg and Langley’s (2004) risky driving scale. In accordance with Beullens et al. (2010, in press) items 1 and 3 were used as a measure for speeding, and item 1 and 2 for fun riding.

Driving after the consumption of alcohol was measured by 2 items. In the last year, how often have you (1) driven a car while you may have had too much alcohol?, (2) driven a car while you definitively had too much alcohol?

It is the aim of the study to test whether the playing of racing and drive'em up games succeeds in predicting emerging adults' speeding, fun riding and driving after the consumption of alcohol. Therefore video game playing, attitudes and intentions were measured at time 1 and self-reported risky driving behavior was measured at time 2 .

\subsection{Analyses}

To assess the relationships between video game playing and speeding (model 1), fun riding (model 2) and driving after consuming alcohol (model 3), a structural equation model was estimated using Amos ${ }^{\mathrm{TM}}$ 17.0. In the current study we are mainly interested in the relationship between racing and drive'em up games, risk taking attitudes, risky driving intentions and self-reported reckless driving. Measures of intensity and aggression were included in the models as potential confounders as it has been shown that these constructs are related to risky driving (Jonah, 1997; Gulliver and Begg, 2004) and media use (Hall, 2005ab). 
Several other variables have been shown to explain specific behavior (cf. Theory of Planned Behavior (Ajzen, 1991)). These constructs were not added to our models since the inclusion of constructs that have been shown to correlate with our dependent variable, but were not hypothesized to correlate with our exposure variables, would have increased the fit of the structural equation models artificially.

\section{Results}

\subsection{Prevalence of video game playing}

Racing games appeared to be very popular among the adolescents’ in our sample. Only 19.1\% of the respondents never played racing games, $28.8 \%$ played them a few times a year, $14 \%$ once a month, $12.8 \%$ a few times a month, $7.4 \%$ once a week, $12.8 \%$ a few times a week and $5.1 \%$ almost every day. Drive'em up games too appeared to be regularly played by the adolescents in our sample. $21.6 \%$ played drive'em up games several times a year, $8.6 \%$ once a month, $17.6 \%$ a few times a month, $9 \%$ once a week, $12.2 \%$ several times a week and 5.5\% almost every day. 25.5\% reported to never have played this game genre.

\subsection{Prevalence of risky driving behavior}

Risky driving regularly occurred among the respondents. $29.4 \%$ admitted to drive to fast because of the thrill of it seldom, $14.1 \%$ sometimes and $8.4 \%$ at least often. Less than half of the respondents (48.1\%) asserted to never exhibit this kind of risky behavior. Driving faster than legally allowed appeared to be even more common. Only $14.8 \%$ never engaged in this behavior, $22.3 \%$ seldom, $26.7 \%$ sometimes and $18.8 \%$ often, $12.5 \%$ very often en $4.9 \%$ always. Taking risks in traffic to make driving more fun occurred among $22.8 \%$ of the respondents seldom, 9\% sometimes and among 3.8\% at least often. This behavior was not reported by $64.5 \%$ of the respondents. 
Driving after the consumption of alcohol was less prevalent in the sample. Nevertheless $14.5 \%$ reported to having engaged in driving while they might have had too much alcohol a few times a year, $2.0 \%$ about once a month, and $2.9 \%$ at least a few times a month. 91.6\% never took the car when they definitely had consumed too much alcohol. $6.4 \%$ drove in this condition a few times a year, and $2.1 \%$ once a month or more.

\subsection{Model 1: The impact of video game playing on speeding}

The theoretical model proposed that the playing of racing and drive'em up games during adolescence is a significant predictor of speeding and fun riding two years later. It is hypothesized that this relationship is mediated by risk taking attitudes and intentions.

In model 1 this relationship was tested for speeding. Maximum likelihood fit indices provided support for the proposed model $\left(\chi^{2}=449.948 ; \mathrm{df}=242 ; \mathrm{CMIN} \backslash \mathrm{df}=1.859 ; \mathrm{p}=.000\right.$, CFI=.911, RMSEA=.049). The RMSEA (this is the 'root mean square error of approximation') "shows 'how well would the model, with unknown but optimally chosen parameter values, fit the population covariance matrix if it were available'. Values less than 0.05 are indicative of a good fit, between 0.05 and under 0.08 of reasonable fit, between 0.08 and 0.10 of mediocre fit and $>0.10$ of poor fit.” (Diamantopoulos and Siguaw, 2000, p. 85). CFI is the Comparative Fit index. This value ranges between 0 and 1 . Values larger than 0.90 indicate that the estimated model fits the data (Kelloway, 1998, p. 31). It has been suggested to also compute the CMINIdf fit index (Arbuckle, 2007). Optimally this "relative chi square" lies within the range of 2 to 5 to indicate a reasonable fit (Arbuckle, 2007, p. 589). Thus the fit indices for the proposed model are acceptable and indicate that the hypothetical model fit the sample data.

However several of the standardized estimates were not significant. Therefore these paths were removed from the model (cf. Aish and Jöreskog, 1990, p. 441). The respecified 
model fitted the data very well and provided support for most of the hypotheses $\left(\chi^{2}=455.199\right.$; $\mathrm{df}=245 ; \mathrm{CMIN} \backslash \mathrm{df}=1.858 ; \mathrm{p}=.000$, CFI=.910, RMSEA=.049) (figure 2). Video game playing appeared to be a significant predictor of attitudes towards speeding (standardized regression coefficient $\gamma=.21$ ). Attitudes $(\gamma=.69)$ were in turn a good (indirect) predictor of self-reported speeding behavior at time 2 , through speeding intentions $(\gamma=.45)$. Together the predictors of speeding behavior explained $40.3 \%$ of its variance.

\section{FIGURE 2: ABOUT HERE}

Subsequently a multiple group analyses for boys and girls was executed. The main objective of these analyses is to test whether the same model applies for several subgroups. It allows to compare groups (i.c. boys and girls) by fitting a model on several datasets simultaneously. As Arbuckle has indicated (2007, p. 161), these multiple group analyses provide more accurate parameter estimates than would be obtained from two separate analyses.

Fit indices indicated that the proposed model counted for boys as well as girls $\left(\chi^{2}=\right.$ 744.018; $\mathrm{df}=490 ; \mathrm{CMIN} \backslash \mathrm{df}=1.518 ; \mathrm{p}=.000, \mathrm{CFI}=.864$, RMSEA=.038). However several of the standardized regression coefficients appeared to be not significant in particular groups. Among boys, physical aggression was not a significant predictor of video game playing. The measure of intensity seeking did not explain a significant part of the variance in speeding behavior among boys and girls and it was not a significant predictor of attitudes among girls. Furthermore video game playing was only a significant predictor of speeding among boys $(\gamma=.22)$, and not among girls. The estimate of the squared multiple correlation of speeding was also higher among boys (31.5\%) than girls (23.2\%). 
3.4. Model 2: The impact of video game playing on fun riding

\section{FIGURE 3: ABOUT HERE}

In model 2 (figure 3) it was examined whether video game playing during adolescence succeeds in predicting a significant part of the variance in fun riding 2 years later. Although the fit indices provided support for the proposed model $\left(\chi^{2}=343.178 ; \mathrm{df}=199\right.$; CMIN $\backslash d f=1.725 ; p=.000, C F I=.937$, RMSEA=.045), several of the standardized regression coefficients were not significant. A new model was estimated without these associations (figure 3, $\chi^{2}=347.094 ; \mathrm{df}=202 ; \mathrm{CMIN} \backslash \mathrm{df}=1.718 ; \mathrm{p}=.000, \mathrm{CFI}=.936, \mathrm{RMSEA}=.045$ ). The playing of racing and drive'em up games was a good predictor of the attitudes toward fun riding $(\gamma=.30)$. In accordance with the hypotheses attitudes were a good predictor of fun riding intentions $(\gamma=.70)$, which in turn succeeded in explaining a significant part $(\gamma=.45)$ of the fun riding behavior during emerging adulthood.

Again multiple group analyses were executed in order to check whether the model applied for girls as well as boys. The model fitted for both groups $\left(\chi^{2}=593.589\right.$; $\mathrm{df}=404$; CMIN $\backslash d f=1.469 ; \mathrm{p}=.000$, CFI=.895, RMSEA=.037) and there were no significant differences found in the strength of the relationships. For girls the model explained 25.2\% of the variance in self-reported fun riding and $29 \%$ for boys.

3.5. Model 3: The impact of video game playing on driving after the consumption of alcohol

FIGURE 4: ABOUT HERE 
Finally our proposed model was tested for the endogenous variable driving after the consumption of alcohol. Following our theoretical framework, video game playing should not have an impact on the attitudes and intentions toward driving after alcohol consumption since drinking alcohol is absent from most game content. The data supported this hypothesis. Although the data provided a good fit for this model $\left(\chi^{2}=342.176 ; \mathrm{df}=199 ; \mathrm{CMIN} \backslash \mathrm{df}=1.719\right.$; $\mathrm{p}=.000, \mathrm{CFI}=.933$, RMSEA=.045) again several of the relationships were non-significant. A renewed version of the model was tested without these associations (Aish and Jöreskog, 1990, p. 441). This model is shown in figure $4\left(\chi^{2}=344.449 ; \mathrm{df}=203 ; \mathrm{CMIN} \backslash \mathrm{df}=1.697 ; \mathrm{p}=.000\right.$, CFI=.934, RMSEA=.044). In line with the hypotheses, video game playing was not significantly related with driving after the consumption of alcohol.

Multiple group analyses were conducted in order to test whether this conclusion applied for both boys and girls. In neither of the subgroups video game playing had a significant impact on the attitudes toward driving after the consumption of alcohol. 


\section{Discussion}

Video game playing is very popular among adolescent boys and girls. This has led researchers to examine the possible effects of video game play. Several researchers have studied the impact of video games on aggressive behavior (cf. Anderson and Bushman, 2001; Bensley and Van Eenwyk, 2001). Although a lot of games involve fast and reckless driving (Beullens, et al., 2008), the impact of this kind of games on self-reported driving behavior has not received much attention in literature. This is particularly remarkable given the fact that traffic crashes remain an important cause of death among young adults (WHO, 2007).

The present study examined the relationship between adolescents' playing of racing and drive'em up games and their self-reported driving behavior two years later with a longitudinal panel survey. The results indicated that, even after controlling for aggression and sensation seeking, the amount of video game playing during adolescence is a significant, indirect, predictor of later risky driving behavior through the attitudes towards risk taking in traffic and the intentions to exhibit this behavior in the future.

Furthermore the data provided support for the proposed theoretical model. In line with cultivation theory it was hypothesized that the relationship between media use and risky driving may be explained by the content of these games. It was expected that the association between racing and drive'em up games and risky driving behavior only existed for these risky driving acts which frequently occur in video games, i.e. speeding and fun riding. Following this line of reasoning no relationship should have been found between video games and driving after the consumption of alcohol since this content is largely absent from about all games. The data provided support for these hypotheses. Thus they seem to suggest that the relationship between media use and risky driving has a connection with game content. However, given the fact that no experimental research has been done, no definitive statement 
can be made on the causality of the relationship between video games and risk taking neither on the reason for this association. Structural equation models offer a test of a theory. They check the extent to which theoretical relationships are supported by data. A good fit of a model suggests that the theoretical structure passed a test many other theoretical models have not passed, but it is not proof of internal or external validity.

Nevertheless, from a prevention point of view the findings of this study are very interesting. They show that young drivers’ risky driving behavior can be predicted before they have obtained their actual driver's license and thus before they pose a risk in traffic for themselves and for other people. This allows prevention campaign planners to address the future risk takers, before they actually take risks. In addition, the results indicate that video game playing is an important aspect of adolescents' lifestyle and should not be neglected when examining traffic related risk taking.

Further research should try to provide a clearer insight into the relationship between media use and risky driving. Several research avenues seem to be important. First, content analytic research on video games as well as on risky driving in other media genres (television fiction, reality television etc.) is largely absent. In order to examine whether media content has an effect on young drivers' risk taking, it is important to gain knowledge in the portrayal of risky driving in different media. Second, experimental research may solve the causality question. However it must be noticed that there may be ethical issues involved in trying to expose young adults to media content which may have adverse effects on their driving behavior. Furthermore cultivation theory argues that it is the long term exposure to a particular content which influences perceptions and attitudes. Such long term effects may be hard to capture in experimental studies.

The present study adds to the limited amount of research on the relationship between media use and risky driving in two ways. It focused on risky driving behavior and it appears 
to have been the first longitudinal study to examine the relationship between both concepts. However there are several limitations. First, as discussed above, even though a longitudinal panel survey was used, the data do not allow establishing causality unambiguously. Second, self-report measures were used to assess risky driving behavior. Although research has shown that these have a good validity when the confidentiality of the study is assured (Campanelli et al., 1987, White, 1991), they remain a non-objective measure of risk taking.

\section{Acknowledgement}

This study was funded by a subsidy from the Flemish Fund for Scientific research (FWO). 


\section{References}

Aish, A.M., Jöreskog, K.G., 1990. A Panel Model for Political Efficacy and Responsiveness: An Application of LISREL 7 with Weighted Least Squares. Quality and Quantity 24, 405-426.

Ajzen, I., 1991. The Theory of Planned Behavior. Organizational Behavior and Human Decision Processes 50, 179-211.

Anderson, C.A., Bushman, B.J., 2001. Effects of violent video games on aggressive behaviour, aggressive cognition, aggressive affect, psychosocial arousal and prosocial behaviour: A meta-analysis. Psychological Science 12, 353-359.

Anderson, C.A., Dill, K.E., 2000. Video Games and Aggressive Thoughts, Feelings, and Behavior in the Laboratory and in Life. Journal of Personality and Social Psychology 78 (4), 772-790.

Arbuckle, J.L., 2007. Amos ${ }^{\mathrm{TM}} 16.0$ User’s guide. Chicago: Amos development Corporation.

Armitage, C.J., Conner, M., 2001. Efficacy of the theory of planned behaviour: A metaanalytic review. British Journal of Social Psychology 40, 471 - 499.

Arnett, J.J., 1994. Sensation Seeking: a new conceptualization and a new scale.

Personality and Individual Differences, 22, 393-401.

Arnett, J.J., 1996. Sensation seeking, aggressiveness, and adolescent reckless behavior. Personality and Individual Differences 20(6), 693-702.

Arnett, J.J., Irwin, C.E., Halpern-Felsher, B.L., 2002. Developmental sources of crash risk in young drivers. Injury Prevention 8(Suppl. 2), 17-21.

Begg, D., Langley, J., 2004. Identifying predictors of persistent non-alcohol or drug-related risky driving behaviours among a cohort of Young adults. Accident Analysis \& Prevention 36(6), 1067-1071.

Bensley, L., Van Eenwyk, J., 2001. Video Games and Real-Life Aggression: Review of 
the Literature. Journal of Adolescent Health 29, 244-257.

Beullens, K., Roe, K., Van den Bulck, J., 2008. Video games and adolescents’ intentions to take risks in traffic. Journal of Adolescent Health 43, 87- 90.

Beullens, K., Roe, K., Van den Bulck, J., 2010, in press. The relationship between adolescents' music video viewing and risky driving: a two wave panel survey. International Journal of Psychology Research 5 (3-4).

Bilandzic, H., Rössler, P., 2004. Life according to television. Implications of genre-specific cultivation effects: The Gratification/Cultivation model. Communications, 29, 295 $-326$.

Billiet, J., Carton, A., 2001. Dataverzameling: gestandaardiseerde interviews en zelf-in-te vullen vragenlijsten. In J. Billiet, H. Waege (Eds.) Een samenleving onderzocht. Methoden van sociaal-wetenschappelijk onderzoek. Antwerpen, Standaard Uitgeverij, nv.

Bina, M., Graziano, F., Bonino, S., 2006. Risky driving and lifestyles in adolescence. Accident Analysis \& Prevention 38, 472-481.

BIVV Belgisch Instituut voor de Verkeersveiligheid, n.d.. BIVV verkeersveiligheid Statistieken 2001. Retrieved September 10, 2006, from http://www.bivv.be/

Buss, A.H., Perry, M., 1992. The Aggression Questionnaire. Journal of Personality and Social Psychology 63, 452-459.

Campanelli, P.C., Dielman, T.E., Shope, J.T., 1987. Validity of adolescents’ self reports of alcohol use and misuse using a bogus pipeline procedure. Adolescence 22(85), 7-22.

Carlo, G., Eisenberg, N., Knight, G.P., 1992. An objective measure of adolescents' prosocial moral reasoning. Journal of Research on Adolescence 2(4), 331 - 349. 
Chliaoutakis, J.E., Darviri, C., Demakakos, P.T., 1999. The impact of young drivers' lifestyle on their road traffic accident risk in greater Athens area. Accident Analysis \& Prevention 31, 771-780.

Chliaoutakis, J.E., Koukouli, S., Lajunen, T., Tzamalouka, G., 2005. Lifestyle traits as predictors of driving behaviour in urban areas of Greece. Transportation Research Part F 8, 413-428.

Cohen, J., Weimann, G., 2000. Cultivation revisited: some genres have some effects on some viewers. Communication Reports 13(2), 99-114.

Cortina, J.M., 1993. What is coefficient alpha? An examination of theory and applications. Journal of Applied Psychology 78(1), 98-104.

Cummings, H.M., Vandewater, E.A., 2007. Relation of Adolescent Video Game Play to Time Spent in Other Activities. Archives of Pediatrics and Adolescent Medicine 161(7), 684-689.

Diamantopoulos, A., Siguaw, J.A., 2000. Introducing Lisrel. A guide for the uninitiated. Sage Publications, London.

Fischer, P., Guter, S., Frey, D., 2008. The effects of risk-promoting media on inclinations toward risk taking. Basic and Applied Social Psychology 30, 1-11.

Fischer, P., Kubitzki, J., Guter, S., Frey, D., 2007. Virtual driving and risk taking: Do racing games increase risk-taking cognitions, affect and behaviors? Journal of Experimental Psychology: Applied 13(1), 22-31.

Fishbein, M., 2000. The role of theory in HIV prevention. Aids care 12(3), 273-278.

Fishbein, M., Ajzen, I., 1975. Belief, Attitude, Intention and Behavior. An introduction to Theory and Research. Reading, Massachusetts: Addison-Wesley Publishing Company. Fishbein, M., Cappella, J.N., 2006. The role of Theory in Developing Effective Health Communications. Journal of Communication 56 (supplement), S1-S17. 
Gerbner, G., Gross, L., 1976. Living with television: The violence Profile. Journal of Communication, spring 26(2), 172-194.

Gerbner, G., Gross, L., Morgan, M., Signorielli, N., 1986. Living with Television: The Dynamics of the Cultivation Process. (pp. 17-40) In Bryant, J., Zillmann, D. (Eds.) Perspectives on Media Effects. London: Lawrence Erlbaum Associates.

Gorely, T., Marshall, S.J., Biddle, S.J.H., Cameron, N., 2007. The prevalence of leisure time sedentary behaviour and physical activity in adolescent girls: An ecological momentary assessment approach. International Journal of Pediatric Obesity 2(4), 227-234.

Gregersen, N.P., Berg, H.Y., 1994. Lifestyle and accidents among young drivers. Accident Analysis \& Prevention 26, 297-303.

Gulliver, P., Begg, D., 2004. Influences During Adolescence on Perceptions and Behaviour Related to Alcohol Use and Unsafe Driving as Young Adults. Accident Analysis \& Prevention 36, 773-781.

Hall, A., 2005a. Audience Personality and the Selection of Media and Media Genres. Media Psychology 7, 377-398.

Hall, A., 2005b. Sensation Seeking and the Use and Selection of Media Materials. Psychological Reports 97, 236-244.

Haynes, C.A., Miles, J.N., Clements, K., 2000. A confirmatory factor analysis of two models of sensation seeking. Personality and Individual Differences 29, 823-839.

Jonah, B.A., 1997. Sensation seeking and risky driving: a review and synthesis of the literature. Accident Analysis \& Prevention 29(5), 651-665.

Kelloway, E.K., 1998. Using Lisrel for structural equation modelling. A researcher's guide. London: Sage. 
Kirsh, S.J., 2003. The effects of violent video games on adolescents. The overlooked influence of development. Aggression and Violent Behavior 8, 377-389.

Lemmens, J.S., Bushman, B.J., 2006. The appeal of violent video games to lower educated aggressive adolescent boys from two countries. Cyberpsychology \& Behavior 9(5), 638-641.

Lucas, K., Sherry, J.L., 2004. Sex Differences in Video Game Play: A CommunicationBased Explanation. Communication Research 31, 499-523.

Malliet, S., 2007. The Challenge of Videogames to Media Effect Theory. Leuven: Katholieke Universiteit Leuven.

Nunnally, J.C., 1978. Psychometric Theory ( $2^{\text {nd }}$ ed.). New York: McGraw-Hill.

Potter, J.W., 1993. Cultivation Theory and Research: 'A conceptual Critique'. Human Communication Research 19(4), 564.

Santos, J.R.A., 1999. Cronbach's Alpha: A Tool for Assessing the Reliability of Scales. Journal of extension 37(2), 2-3.

Ulleberg, P., Rundmo, T., 2002. Risk-Taking Attitudes Among Young Drivers: the Psychometric Qualities and Dimensionality of an Instrument to Measure Young Drivers' Risk-Taking Attitudes. Scandinavian Journal of Psychology 43(3), 227-237.

Ulleberg, P., Rundmo, T., 2003. Personality, attitudes, and Risk Perception as Predictors of Risky Driving Behaviour Among Young Drivers. Safety Science 41(5), 427-443.

Van Mierlo, J., Van den Bulck, J., 2004. Benchmarking the cultivation approach to video game effects: a comparison of the correlates of TV viewing and game play. Journal of Adolescence 27, 97-111.

White, H.R., 1991. Marijuana use and delinquency: a test of the 'independent cause' hypothesis. Journal of Drug Issues 21(2), 231-256. 
Williams, D., 2006. Virtual Cultivation: Online Worlds, Offline Perceptions. Journal of Communication 56, 69-87.

World Health Organization. World report on road traffic injury prevention - Main messages. 2004. Downloaded from http://www.who.int/violence_injury_prevention/publications/road_traffic/world_report /factsheets/ (accessed 2 Oct 2007). 
Figure 1: Hypothetical model

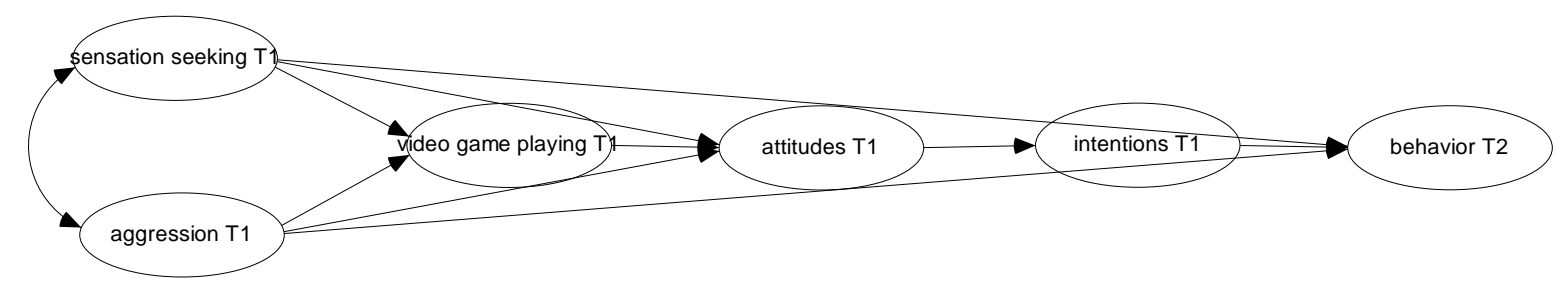

Figure 2: Model 1: The impact of video game playing on speeding

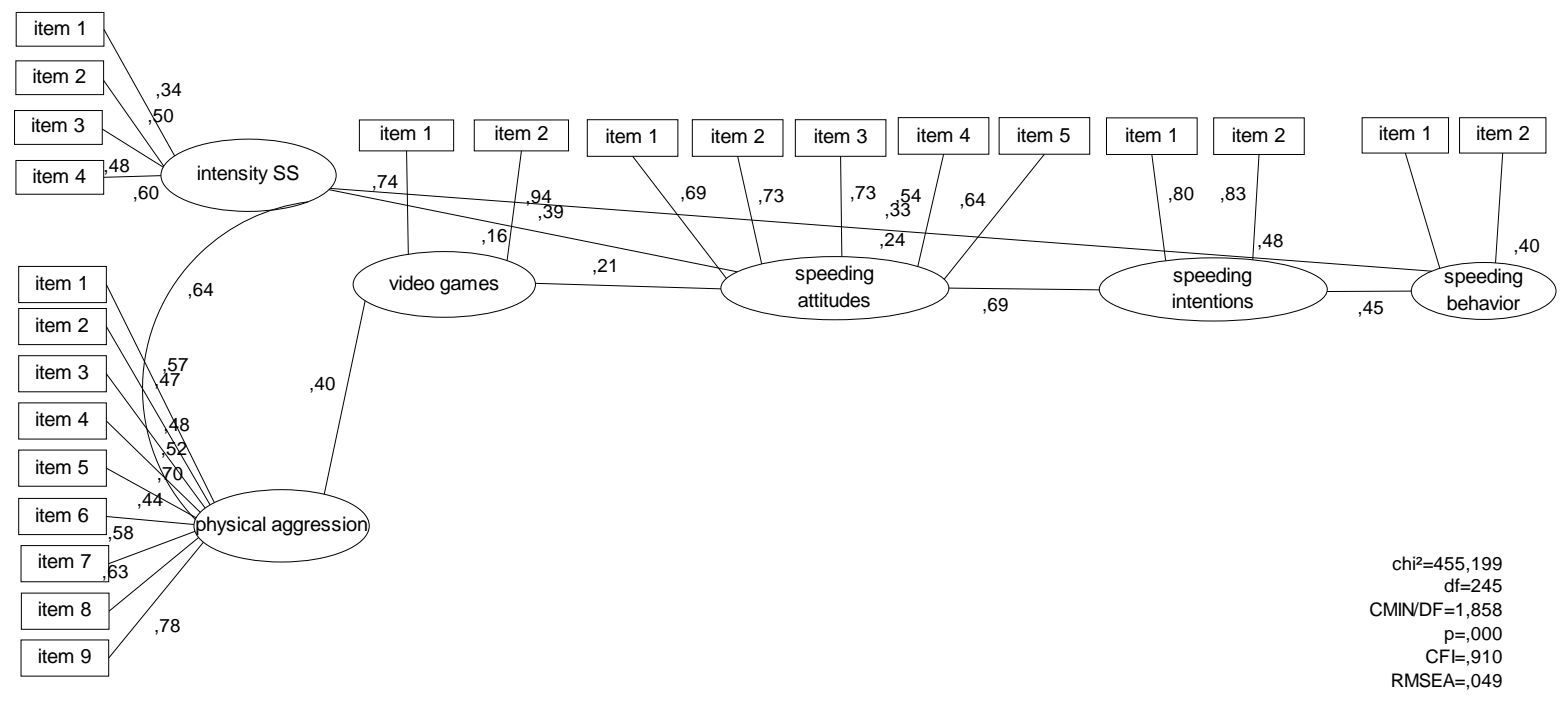

All regression coefficients are significant at $\mathrm{p}<.01$ level 
Figure 3: Model 2: The impact of video game playing on fun riding

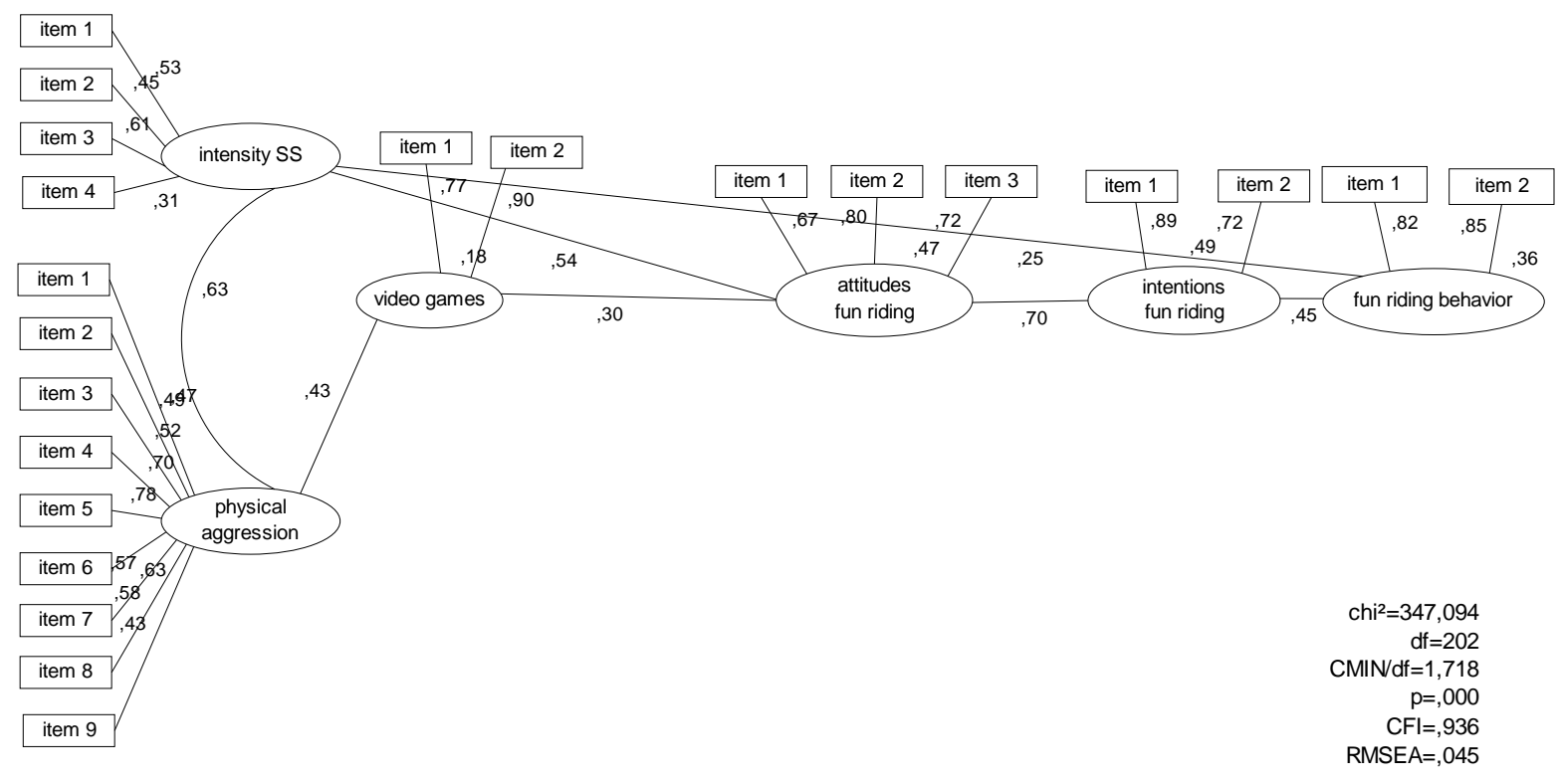

All regression coefficients are significant at $\mathrm{p}<.01$ level

Figure 4: Model 3: The impact of video game playing on driving after the consumption of alcohol

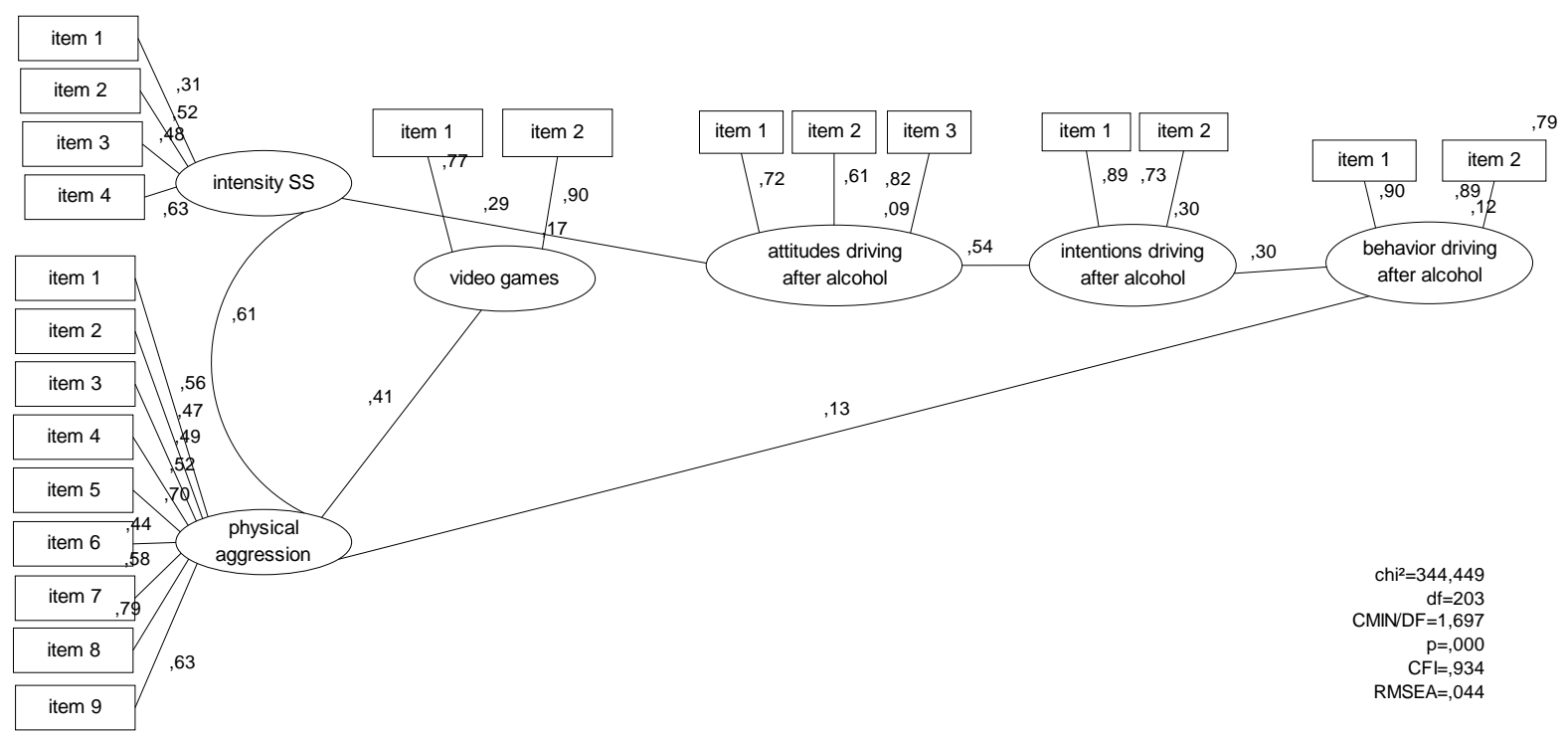

All regression coefficients are significant at $\mathrm{p}<.05$ level 